\title{
DESIGN, TESTING AND EVALUATION OF PROTOTYPE BIOFILTER TO MITIGATE ODOR IN TUNNEL-VENT POULTRY PRODUCTION SYSTEM
}

\author{
J. EBOŃA ${ }^{1} \&$ M. LANUZO ${ }^{2}$ \\ ${ }^{1}$ Associate Professor III, CBSUA, Pili Camarines Sur Philippines \\ ${ }^{2}$ Professor VI Bicol University, Legazpi City, Philippines
}

\begin{abstract}
Industrial farm animals such as broilers housed in large tunnel-vent poultry system provide for a protein source of close to 100 million Filipinos. An efficient animal production facility, tunnel-vent system operates on a Climate Controlled System (CCS) which is controlled by a central computer. However, in the Philippines, there were recorded evidences of system malfunction and failure posing a great public concern due to obnoxious gases which inevitably attract household flies flocking nearby communities.

This research delved on an in-depth study on the mechanism of operations of a tunnel-vent poultry production system in the northeastern part of the Philippines and used the baseline data to design, test and evaluate a prototype biofilter to mitigate odor as the gist of the study.

The designed simple, low-cost and environment-friendly prototype biofilter is made up of locally available materials. It is composed of a plenum, an exhaust fan and a supporting structure. The plenum is subdivided into four (4) drawers separated by screens to house filter media. Series of drawers was conceived in anticipation of choice and density of biomass filter materials. The exhaust fan which is $30.48 \mathrm{~cm}(12$-in $\varnothing)$ operates on a suction mechanism which guides and pushes the air to pass through the filter media by as much as $230 \mathrm{cfm}$. The supporting structure provides for stability and protection of the biofilter and the exhaust fan.

Performance evaluation showed positive and promising result. Thus, further study on upscaling and field testing of the biofilterin actual tunnel-vent system for odor mitigation is necessary.

Keywords: ammonia, biofilter, biofiltration, filter media, gas reduction efficiency, hydrogen sulfide, mechanically decorticated coco coir, odor mitigation, tunnel-vent poultry system.
\end{abstract}

\section{INTRODUCTION}

To date, animal husbandry has gone far but the realization of environmental health has not been given due attention and sometimes being neglected to the fullest, creating nuisance to public health because of its high-strength waste and its associated foul odors.

Odor is a major issue confronting poultry owners in the Philippines. As much as possible regulatory authorities wish to ensure that neighbors will not experience odor nuisance. Nuisance occurs when the frequency, intensity, duration, context and offensiveness of the odor cause unreasonable interference with a neighbor's lifestyle [1].

To address this issue, technologies for removal of hazardous pollutants from the air have gained increased importance following the requirements of Republic Act 8749 or the Philippine Clean Air Act [2].

Biofiltration is an emerging and attractive technology for the removal of nuisance odors. Compared to other technologies, it is cheap and reliable. More importantly, biodegradable VOCs can be degraded to non-hazardous products such as carbon dioxide and water without the generation of other secondary wastes. However, their applicability in the Philippines is limited since only few animal production facilities operate on mechanically ventilated or tunnel-ventilated (tunnel-vent) system.

An efficient animal production facility, tunnel-vent system operates on a Climate Controlled System (CCS) which is controlled by a central computer from the different 
environmental variables such as temperature and relative humidity to the metering of feeding and watering operations. However, there were recorded evidences of system malfunction and failure such that it poses great public concern due to obnoxious gases and the outbreak of household flies flocking the nearby communities.

This study aimed at providing benchmark information on the mechanism of operations of the tunnel-vent poultry production system in the northeastern part of the Philippines, a tropical country where the warm temperature enhances anaerobic decay and foul odor production. Likewise, gathered baseline data were used to design, test and evaluate a prototype biofilter to mitigate odor. The study had the following objectives (1) Analyze the animal production building in terms of building design and the presence of the applicable treatment facilities, (2) Find out the waste management practices employed and their contribution to the management; (3) Assess compliance of tunnel-vent farms with Initial Environmental Examination (IEE) checklist; and (4) Identify the problems being encountered in waste management; and (5) Design, test and evaluate prototype biofilter using mechanically decorticated cococoir fibers as filter.

The locale of the study was three (3) tunnel-ventilated poultry farms purposively selected and coded as Tunnel-vent Farm A, B and C which were located in Calabanga and Pili, Camarines Sur, which are both located in the Northeastern part of the Philippines. Geographical coordinates were determined using GPS Unit with WGS 84 datum for the project location under study. Farm A is N13 ${ }^{\circ} 37.100^{\prime}$ E $123^{\circ} 12.190^{\prime}$ Farm B, N13 ${ }^{\circ} 43.861^{\prime}$ E123 $12.190^{\prime}$ and Farm C is $\mathrm{N} 13^{\circ} 36.880^{\prime} \mathrm{E} 123^{\circ} 16.195^{\prime}$.

Figure 1 shows the paradigm of the theoretical framework.

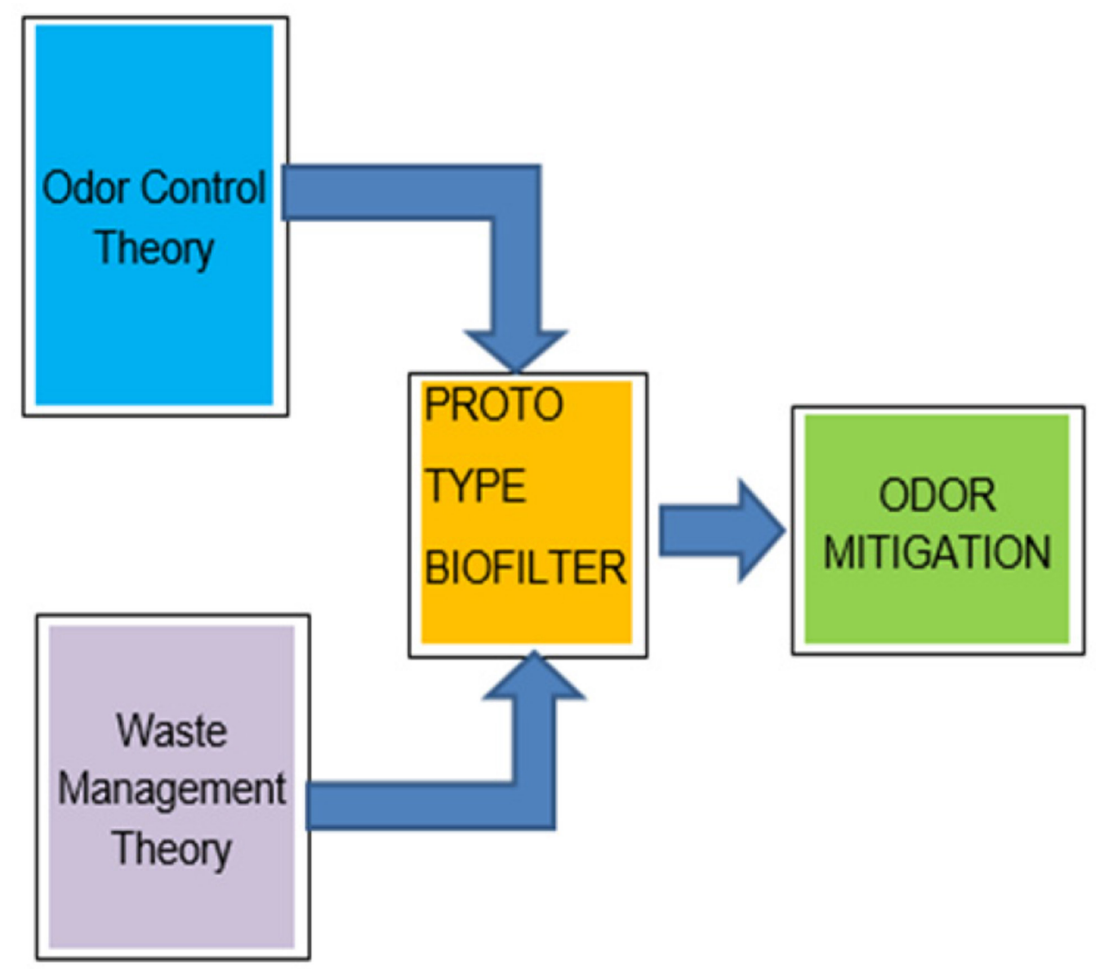

Figure 1: Theoretical Framework. 
The Odor Control Theory by G. Kiely is based on the hypothesis that where there are no wet wastes, there are no odors. Moisture content affects reactions that occur in decomposing materials. The higher the water content, the less oxygen is present, again causing intense odors. Water in decomposing material can also become volatile and produce odors that mix with the air. Lower levels of moisture can slow biological reactions that produce odors.

The Theory of Waste Management by E. Pongracz represents a more in-depth account of the domain and contains conceptual analysis of waste, the activity upon waste, and a holistic view of the goals of waste management. Waste management theory is founded on the expectation that waste management is to prevent waste causing harm to human health and the environment.

These two theories together formed part of the framework of the study. Mechanical ventilation is very effective in removing gases and dust from production barns, but it emits these compounds into narrow highly concentrated plumes. Biofilters will reduce the amount of dust that will travel downwind from a mechanically ventilated facility. Frequent cleaning and good housekeeping practices and waste management schemes are helpful in odor reduction.

\section{MATERIALS AND METHODS}

The study made use of both qualitative and quantitative research methods employing descriptive and quasi-experimental research to answer the problems of the study. Structured questionnaires were devised and administered to the tunnel-vent poultry operators for the qualitative research phase of the study while the actual design, fabrication and performance evaluation constitute the quantitative research phase. Ocular inspection of tunnel-vent farms and triangulation substantiated the data gathering activities. It was undertaken from February 2015 to February 2016. Proprietors of each tunnel-vent system provided permission and access for the collection of data.

A simple, low-cost, downscaled prototype biofilter was designed and fabricated. The design was based on the Empty Bed Retention Time (EBRT) in seconds, airflow rate in cfm and the mechanically decorticated coco coir fibers as filter media. For tunnel-vent poultry system, EBRT considered was 3 seconds [3] while the computed airflow rate was $2.12 \mathrm{cfm}$. Figure 2 is the perspective design of the biofilter.

The prototype biofilter can be retrofitted in any structure tunnel-vent for that matter. It can also find immediate application or niche in public comfort rooms. Made up of locally available materials, the prototype biofilter is composed of a plenum, an exhaust fan and a supporting structure. The plenum is subdivided into four (4) drawers separated by screens to house filter media. Series of drawers was conceived in anticipation of choice of filter materials and proportion. Mechanically decorticated coco coir fibers (untreated) were used as filter media. The exhaust fan which is $30.48 \mathrm{~cm}$ (12-in) in diameter operates on a suction mechanism which guides and pushes the air to pass through the filter media by as much as $230 \mathrm{cfm}$. The supporting structure provides for stability and protection of the biofilter and the exhaust fan.

The fabrication was done at RebTech Enterprises in Bigaas, Calabanga, Camarines Sur, while evaluation was done at the CRL Calabarquez Corporation in LIIP, Bińan, Laguna, both situated in the Philippines. Proper storage was observed to avoid cross-contamination during transportation. However, prior to final evaluation, a series of pre-testing activities was done accordingly to determine its functionality and likewise, come up with the desired amount of filter media in the compartment.

[4] Methods of air sampling and analysis (MASA) employed were the acceptable methods and standards approved by the Department of Environment and Natural Resources (DENR) 


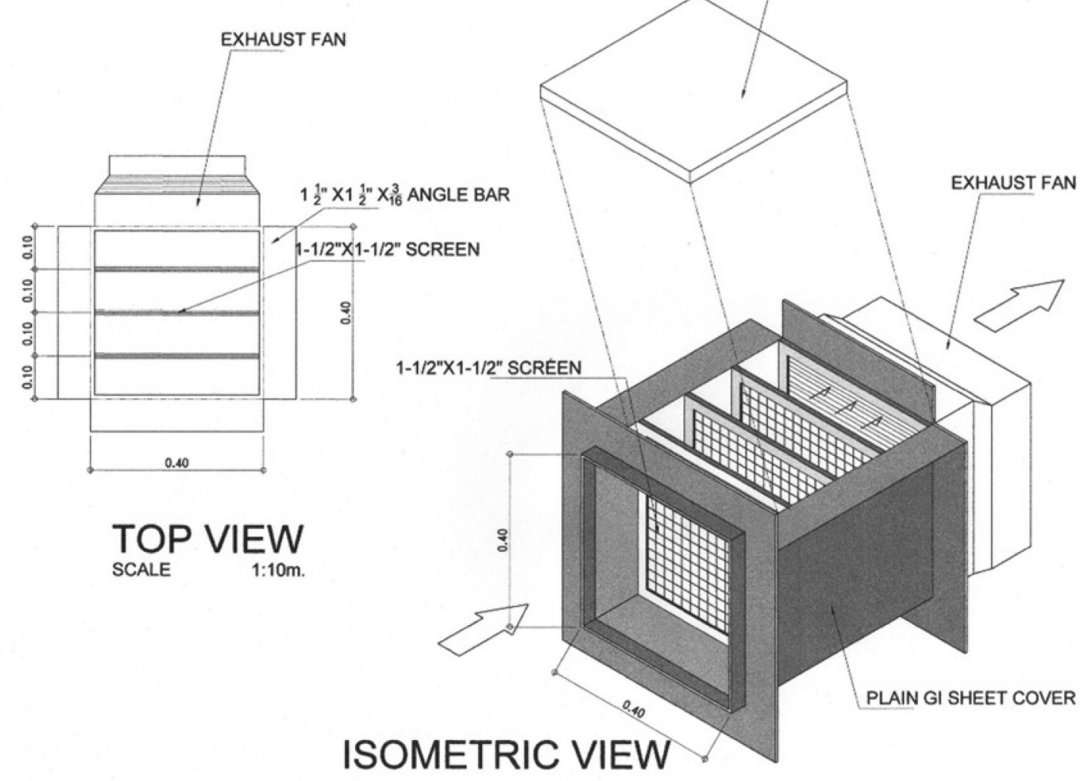

Figure 2: Isometric View of the Biofilter.

of the Philippines. Gas monitored were ammonia (sharp, pungent odor) and hydrogen sulfide (rotten egg odor). Aforesaid gases are significant gases which are results of decomposition of animal wastes which could pose significant bad odor. Three (3) replicates were made during the evaluation of the prototype biofilter.

[5] For the test materials, physico-chemical properties of coco coir fibers and poultry dung were determined. Two hundred fifty (250) grams each of mechanically decorticated untreated coco coir fibers with $15.4 \% \mathrm{MC}, 85.7 \%$ porosity and $1.12 \mathrm{~g} / \mathrm{cc}$ bulk density were used per trial. Likewise, composite samples of a week old poultry dung were obtained from Tunnel-vent Farm C, located in Pili, Camarines Sur, Philippines. One kilogram poultry dung each per trial was used. It was found out that it has $52.7 \% \mathrm{MC}, 72.2 \%$ porosity and $2.56 \mathrm{~g} / \mathrm{cc}$ bulk density (Fig. 3).

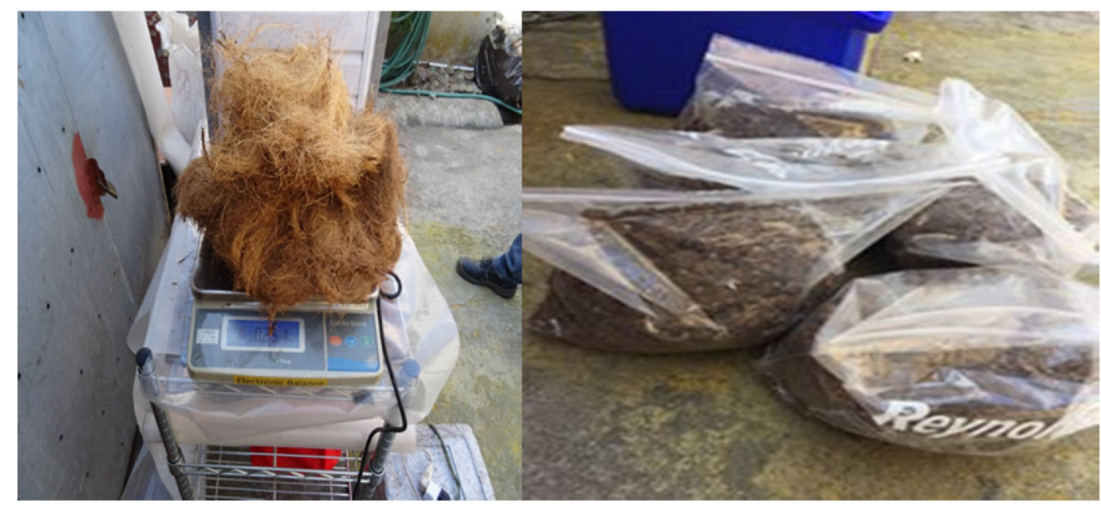

Figure 3: Test materials as filter media and odor source. 
Gas removal efficiency was computed based on the formula of gas concentration in the inlet minus gas concentration at the outlet divided by the gas concentration at the outlet multiplied by $100 \%$. It is the ultimate goal of the biofilter to reduce the gas concentration that is called odor mitigation.

Data was analyzed using simple statistical tools such as means and percentages.

\section{RESULTS AND DISCUSSION}

The requirements prior to tunnel-vent establishment is stipulated in the (IEE) checklist provided for by the (DENR) of the Philippines [6]. Aforesaid checklist must be complied with accordingly.

The overall benchmark of the three tunnel-farms provided standard facilities and accessories inherent in the establishment of a tunnel-vent poultry system. Likewise, said facilities/ accessories adhere to the Philippine Agricultural Engineering Standards for animal production facility.

The genotype of poultry and other inputs of production such as feeds are provided by the integrators of the three tunnel-vent farms. What the tunnel-vent have to do is to take care of them every production cycle by maintaining the desired climate within the system as per the age of the chickens.

\subsection{Tunnel vent waste management practices and problems encountered}

Part of the tunnel-vent industrial ecology is the waste management practices. Thus, in this study, it was deemed necessary to evaluate existing waste management practices of tunnelvent systems under scrutiny.

The three respondents - Farm A, B, and C, are all contract growers of a leading corporation in the Philippines as integrators. As such, commercial feeds are distributed solely by the integrators. Farm A, B, and C were able to utilize feeds; 450, 152, 260 bags of booster, respectively, for 7 days; 275, 190, 300 bags of starter, respectively, for 4 days; 800, 560, 650 bags of growers, respectively, for 14 days; and 175,122,175 bags of finisher for 3 days. The feeds are delivered every loading period and should be consumed within the production cycle. Thus, the management follows the First In, First Out (FIFO) Rule. Likewise, the feeds were stored using wooden pallet to serve as precautionary measures in protecting the quality of the feeds. One production cycle lasted for $28-33$ days, depending upon the request of the integrators. Farm A, B, C were able to achieve 8, 7, $7-8$ production cycles per year, respectively.

The cleaning of manure and the whole facility is being done after every harvest. Feeders and waterers were raised up high to be able to put at the side all plastic slats so that manure can be collected. In Farm A, solid waste was treated with Agita, a chemical spray for flies before disposal, while Farm B and C manure underwent fumigation using Dichlorvos chemical at about 500 liters. Solid wastes were collected manually using shovel and placed in sacks for disposal. After which, they will be collected and delivered to respective clients.

When all the solid waste has been removed from the facilities, there will be cleaning of the whole area, including the plastic slats, waterers, and feeders using power hose sprayer. When everything has been cleaned, all ventilation of the facilities is opened to let the fresh air enter the building before they disinfect the area. Aldecol disinfectant was used in Farm A while Vernon disinfectant is used in Farm B and $\mathrm{C}$ to have them ready for the next production cycle. 
The wastewater goes directly to the septic tank located at the rear end of the tunnel vent facility for Farm A and C, while for Farm B, it goes directly to the semi pond near the area, which was originally intended for planting rice but was converted into a liquid waste treatment facility for repository purposes. After a week or two, depending upon the request of the contract grower integrators, the facility is being prepared for the next production cycle.

Minimizing pollution risks from point sources depends on proper designing, constructing and managing facilities. From an engineering perspective, "properly designed and constructed" facilities are those that satisfy the purpose at a minimum cost, consistent with accepted factors of safety. The intended purposes of controls for most agricultural point sources of pollution are to contain pollutants and prevent their uncontrolled release to the environment. The basic requirements for such facilities are adequate storage capacities, structural integrity and careful site locations [7].

The idea of industrial ecology in tunnel-vent system is well integrated and practiced. Treatment facilities function well for pollution prevention and the waste materials are used as inputs to other production system like the manure is sold as farm inputs in farms and fishponds.

However, problems are seen as an inevitable factor in operations and management of any system. Thus, tunnel-vents are not exempted from problems. Though minimal but these can cause much damage if not properly addresses like the malfunction of the controlled system using computers, which was usually noted when there is a fluctuation of power supply. Similarly, heat stroke among birds manifest when the ventilation within the system is not adequate.

Likewise, unpleasant odor is evident due to improper housekeeping practices of erring caretakers detailed at the tunnel-vents especially when the owner is not around. Likewise, another identified problem was the odor, which is evident and emanates when wastes are agitated during cleaning operations for 2-3 days. This happens after the market disposal of the chickens at the end of each production cycle.

Moreover, use of chemical spray as disinfectant pose hazards to the environment, wastes from tunnel-vent may have bio-accumulative effect to the environment considering that the wastes are used in farms and fishponds as inputs for farm production intended for food. Organic agriculture despises the use of chemical-laden inputs.

\subsection{Prototype biofilter design, fabrication and performance evaluation}

The gist of the study was the design, fabrication and performance evaluation of the prototype biofilter. The identified problems mentioned above paved the way to the design and fabrication of a prototype biofilter as an alternative technique to mitigate odor, in lieu of hazardous chemicals.

Solutions are needed to deal with the problem of odorous compounds and airborne contaminants emitted from animal agriculture. Odor and airborne contaminant emissions have always been a part of the livestock and poultry industry [8].

The designed prototype biofilter consists of locally available yet durable materials such as metal with a mesh wire to support and contain the filtering bed. It is basically composed of (1) a supporting structure containing the bed, (2) air plenum to distribute the exhausted air evenly across the biofilter media using (3) exhaust fan of appropriate specifications to exhaust air at the rear portion. Likewise, it conforms with the Philippine Agricultural Engineering Standards or PAES for air pollution mitigation [9]. Machine specifications are shown in Table 1. 
Table 1: Prototype Biofilter Specifications.

\begin{tabular}{ll}
\hline Particulars & Specifications \\
\hline BiofilterDimension, cm & \\
Length & 40 \\
Width & 40 \\
Height & 40 \\
Weight, kg & 20 \\
Source of power & Electricity \\
Labor requirement & 1 \\
Exhaust Fan & \\
Diameter, cm & $30.48 \mathrm{~cm}$ \\
Model & REPW03/14 \\
Power, W & 33 \\
Rated voltage, V & 230 \\
Wind & $6.5 \mathrm{~m}^{3} / \mathrm{min}$ or $230 \mathrm{cfm}$ \\
Brand & Royu \\
\hline
\end{tabular}

\subsubsection{Material testing of coco coir and poultry dung}

Series of physico-chemical characterization such as moisture content, \% porosity, for the test materials (i.e. cococoir fibers and poultry dung) were also undertaken wherever applicable. The aforesaid characterization study had a bearing on the performance of the prototype biofilter.

Porosity is crucial since contaminated air needs to be able to move freely through the packing material without stagnating or clogging, both of which reduce biofilter performance. The moisture content of the influent air stream is critical; air that is too dry may dry the biofilm and the filter media [10]. Bulk density is defined as the dry weight of materials per unit volume of materials. The lesser the bulk density the more it is advantageous in terms of storage and transport.

Table 2 reveals the physico-chemical characteristics of the test materials. The chicken dung has a moisture content of $52.7 \%$, porosity of $72.2 \%$ and a bulk density of $2.56 \mathrm{~g} / \mathrm{cc}$ while coco coir has $15.4 \%, 85.7 \%$ and 1.12 , respectively. The said physico-chemical properties had a bearing on the performance of the biofilter.

Bulk density and porosity are helpful in the design of the biofilter. These are inherent characteristics of a material. The lower the value of the bulk density the more it becomes an advantage in the design of a system. However, the higher the percentage of porosity, the

Table 2: Summary of Physico-chemical Test Results for Chicken Dung and Coco Coir.

\begin{tabular}{lll}
\hline Parameters & Chicken Dung & Coco Coir \\
\hline MC, \% & 52.7 & 15.4 \\
Porosity, \% & 72.2 & 85.7 \\
Bulk density, g/cc & 2.6 & 1.1 \\
\hline
\end{tabular}


Table 3: Significant weather elements \& parameters during the final evaluation.

\begin{tabular}{llll}
\hline Parameters & Inlet & Outlet & Average \\
\hline Ave. flowrate*, $\mathrm{L} / \mathrm{min}$ & 1 & 1 & 1 \\
Ambient temperature, ${ }^{\circ} \mathrm{C}$ & 31.5 & 31.7 & 31.6 \\
Atm pressure, $\mathrm{mm} / \mathrm{Hg}$ & 760 & 760 & 760 \\
Relative Humidity, $\%$ & 32.1 & 32.2 & 32.2 \\
Air velocity, $\mathrm{m} / \mathrm{s}$ & 1.4 & 1.4 & 1.4 \\
\hline
\end{tabular}

* Pre-set by CRL during testing

higher are the void spaces where microorganisms in the coco coir could cling and thrive. These microorganisms are said to degrade the organic gases in the biofilter system.

Table 3 presents the significant weather elements \& parameters during the final evaluation. These were obtained from the equipment and methods undertaken by the CRL Calabarquez Corporation like the ambient temperature, atmospheric pressure, relative humidity and air velocity. Aforesaid environmental variables simulate the climate inside the tunnel-vent for a particular period of time.

The summary of the biofilter test results is shown in Table 4. Gases such as ammonia and hydrogen sulfide were considered in the performance testing. Such gases represent the byproducts of decomposition of animal wastes like the poultry dung.

It further revealed the gas concentration at the inlet and the outlet portion of the prototype biofilter. An average of $0.23 \mathrm{mg} / \mathrm{m}^{3}$ ammonia concentration was noted at the inlet and was noted to reduce at $0.18 \mathrm{mg} / \mathrm{m}^{3}$ at the outlet. Inlet is a point in the biofilter where air passes through the sample poultry dung and the outlet is the part where it passes through the filter media using coco coir fibers. Thus, inlet and outlet represent the before and after filtration phases, respectively.

The presence of hydrogen sulfide gas was not detected during the performance evaluation, however.

Nevertheless, the reduction efficiency, which is the final indicator of functionality and efficiency of the prototypebiofilter was calculated at $30.68 \%$. This implies that malodorous gases can be reduced by $30.68 \%$ of the concentration using the prototype biofilter using one (1) compartment only of the plenum. This could be translated to a better mitigation if the area of filtration will be increased, that is, the utilization of adjoining series of drawers or compartment for biofiltration may be necessary.

The result is acceptable for this pioneering research because from the study of Scholtens, et al., biofilters set up in livestock facility in Netherlands obtain a gas reduction efficiency of $50 \%$. These biofilters were based also on the Zeisig design and decreased hydrogen sulfide and ammonia by $50 \%$.

Table 4: Summary of Biofilter Test Results for Significant Gases.

\begin{tabular}{llll}
\hline Gas Concentrationmg/m & Inlet & Outlet & Gas Removal Efficiency, \% \\
\hline Ammonia $\left(\mathrm{NH}_{3}\right)$ & 0.23 & 0.18 & $30.68 \%$ \\
Hydrogen sulphide $\left(\mathrm{H}_{2} \mathrm{~S}\right)$ & $\mathrm{ND}$ & $\mathrm{ND}$ & $\mathrm{ND}$ \\
\hline
\end{tabular}




\section{HIGHLIGHTS OF FINDINGS, CONCLUSION AND RECOMMENDATION}

The following summarizes the findings on the tunnel-vent poultry facilities under study, to wit: (1) The building designs of the Tunnel-vent Farm A, B and C are efficient in mitigating odor during the production period, but when the manure is agitated during cleaning time, noxious odors are evident. Septic tanks function well in treating liquid waste. (2) Chemical spray and disinfectants in treating manure for waste management contribute in mitigating the odor. (3) Tunnel-vent farms under study are compliant with IEE checklist requirements as contract growers of a leading corporation in the poultry business. Thus, they strictly adhere to the protocol set forth in the requirements and operations vis-à-vis waste management techniques of said corporation; (4) Untrained and unskilled personnel, common practices and improper disposal of liquid waste caused problems in waste management; and source of air pollution or bad odors emanate after market disposal of birds when the poultry wastes are agitated and collected manually by scraping during the cleaning operations of the tunnelvent. (5) Designed prototype biofilter can mitigate odor from ammonia gas from tunnel-vent system through gas reduction efficiency of $30.68 \%$. However, hydrogen sulfide was not detected during the evaluation. Along with good housekeeping practices, the prototype biofilter could find immediate application or niche in urinals and/or public comfort rooms to reduce bad odor.

Based on the findings of the study, the researcher arrived at the following conclusions: (1) Building designs of tunnel-vent farms $\mathrm{A}, \mathrm{B}$ and $\mathrm{C}$ are all efficient in terms of function and operation, and conform to the Philippine Agricultural Engineering Standards or PAES, (2) Aside from industrial ecology/waste management practices being observed in tunnel-vent poultry farms A, B and C; harmful chemicals such as Agita, Dichlorvos, Vernon and Aldecol are used to control odor, (3) Tunnel-vent Farms A, B and C are compliant with IEE requirements since they are contract growers which adhere to the protocol set forth by a leading corporation as integrator, (4) Personnel inadequate housekeeping practices and electrical shortages which affect the system are problems contributing to odor problems, and (5) The prototype biofilter can be used as an alternative mitigating technique in tunnel-vent in lieu of hazardous chemicals which has a bioaccumulative effect in the environment.

With the findings at hand on the waste management practices, areas needing improvement include (1) The tunnel-vent poultry facilities should be closed during removal of manure until they are all packed for disposal, (2) There should be a provision of biofilter at the rear end of the building as an alternative technique to mitigate odor while manual scraping of poultry dung is going on because unpleasant odor lasted for 2-3 days, (3) Constant checking and monitoring of the Compliance in IEE are deemed necessary, (4) There should be personnel and workers' training on good housekeeping practices and pollution prevention; planting of buffer trees around the periphery to shield unpleasant odors to the surrounding vicinity; troubleshooting of CCS and electrical layout, (5) Harmful chemicals like Agita, Dichlorvos, Vernon, and Aldecol which had possible bio-accumulative effect which can damage the environment must be replaced, and (6) Further study on the use of all the compartments/drawers in the plenum be made to further tests gas removal efficiency by increasing amount of biofilter media (coco coir fibers) along with the amount of poultry dung as test materials.

\section{REFERENCES}

[1] www.wvu.edu/ agexten/agency/animal.html

[2] Philippine Clean Air Act, available at http://projects.wri.org/sd-pams-database/philippines/clean-air-act 
[3] Lide, C. \& Howard, N., Biofilters in Animal Agriculture. University of Idaho, Idaho, United States of America, 2014.

[4] Peralta, R.G., Personal Communication, February 2016. Head, Air Quality Monitoring Division, CRL Calabarquez Corporation, Binan, Laguna, Philippines.

[5] Ebońa, J.M., Laboratory Exercises in Agricultural Waste Management, Camarines Sur State Agricultural College, Pili, Camarines Sur, Philippines. 2009.

[6] Arandia, S., Best Management Practices (Tunnel-Vent) of Broiler Production in Camarines Sur. Unpublished Undergraduate Thesis 2015. Central Bicol State University of Agriculture, Pili, Camarines Sur, Philippines.

[7] Henry, S. \& Heinke, G., Environmental science and engineering. Air Pollution and Its Control, 1996.

[8] Taking Odor Mitigation to the Next Level: A Priority for Iowa Agriculture. Table of Technologies: Tier 1, Tier 2 and Emerging, NRC, 2003.

[9] Philippine Agricultural Engineering Standards (PAES) Vol 414-1 and Vol 414-2. 2001, available at amtec.uplb.edu.ph

[10] Schmidt, D., Jacobson, L. \& Nicolai, R., Biofilter Design Information. 2004, available at http://www.extension.umn.edu/agriculture/manure-management 